\title{
High perceived discrimination and no family support increase risk of poor quality of life in gender dysphoria
}

\author{
Surilena Hasan*, Yovita Alviany**, Cerellia Clarissa**, and Sonia Sudana Kusuma**
}

ABSTRACT

\section{BACKGROUND}

Family support and low discrimination perceptions are a factor in protecting against mental disorders and poor quality of life in male to female (MtF) gender dysphoric individuals. The aim of this study was to determine the role of family factors, peer support, self-esteem, perceived discrimination, depression, anxiety, and stress on the quality of life among MtF gender dysphoric individuals.

\section{METHODS}

A cross-sectional study was conducted involving $106 \mathrm{MtF}$ gender dysphoric individuals of Sanggar Swara Jakarta. Respondents filled out questionnaires on demographics, WHOQL-BREF, perceived discrimination, Rosenberg self-esteem, family support, social support (SSQ6), family relations (FACES III), and depression anxiety stress scale (DASS). Simple and multivariate logistic regression tests were used to analyze the data.

\section{RESULTS}

Among the $106 \mathrm{MtF}$ gender dysphoric individuals of Sanggar Swara Jakarta with an age range of $18-45$ years, $78.3 \%$ had no family support, $64.1 \%$ no peer support, $62.3 \%$ high perception discrimination, $64.1 \%$ low self-esteem, $36 \%$ extreme family relations, $44.3 \%$ depression, $59.4 \%$ anxiety, $35.8 \%$ stress and $62.3 \%$ poor quality of life. Employment, perception of discrimination, self-esteem, family support, and anxiety were significantly associated with quality of life $(\mathrm{p}<0.05)$. Multiple logistic regression analysis showed that perceived discrimination(Odds Ratio $=13.89 ; 95 \%$ CI: 5.89-11.99), and family support (Odds Ratio=29.11;95\% CI: 2.45-8.21) were significantly associated with quality of life.

\section{CONCLUSION}

High perceived discrimination and no family support increase the risk of poor quality of life in $\mathrm{MtF}$ gender dysphoric individuals. These findings suggest the need for prevention and intervention of stigmatization and discrimination that should have a special focus on families with $\mathrm{MtF}$ gender dysphoric individuals.

Keywords: Quality of life, family support, perceived discrimination, gender dysphoria
*Department of Psychiatry,

Faculty of Medicine, Atma Jaya

Catholic University of Indonesia

**Medical Profession Program,

Faculty of Medicine, Atma Jaya

Catholic University of Indonesia

\section{Correspondence:}

Dr. dr. Surilena Hasan, Sp.KJ(K)

Department of Psychiatry,

Faculty of Medicine,

Atma Jaya Catholic University of Indonesia

Jl. Pluit Raya No. 2, North Jakarta Indonesia

Phone: +6221-6693168

Fax:+6221-6606123

Email: surilenahasan@yahoo.co.id or surilena@atmajaya.ac.id

Date of first submission, June 2, 2017

Date of final revised submission,

November 10, 2017

Date of acceptance, November 13, 2017

This open access article is distributed under a Creative Commons AttributionNon Commercial-Share Alike 4.0

International License

Cite this article as: Hasan S, Alviany Y, Clarissa $\mathrm{C}$, et al. High perceived discrimination and no family support increase risk of poor quality of life in gender dysphoria. Univ Med 2017;36: 187-96. doi: $\quad 10.18051 /$ UnivMed.2017 v36.187-196 


\section{INTRODUCTION}

Lesbian, gay, bisexual, and transgender (LGBT) has been the hot topic of conversation in Indonesian society for decades. The LGBT community has long existed in Indonesia but only in recent decades has it become phenomenal. The LGBT community began to present itself in various mass media and some cases of samesex marriage emerged openly, along with the formation of communities with a clearly visible structure. ${ }^{(1)}$ A transgender or gender dysphoria individual is an individual who expresses his gender identity as being opposed to his biological gender. There are 2 types of gender dysphoria communities, namely male to female (MtF) and female to male (FtM). The MtF gender dysphoria community is considerably more numerous than the FtM gender dysphoria community, with a 1:1 to $6.1: 1$ ratio. The number of gender dysphoric individuals continues to increase worldwide. It is estimated that by 2030 , the number of gender dysphoric individuals will increase by two-fold. ${ }^{(2)}$ Survey in the United States by Bockting, et al. ${ }^{(3)}$ in 1093 gender dysphoria $\mathrm{MtF}$ (57.5\%) and FTM gender dysphoria $(42.5 \%)$ showed that there were 464 (56.5\%) gender dysphoria MtF with high economic status. Gender dysphoria MtF depression is more likely to be discriminated (verbal 37\%, physical 20\%, work 39\%) compared to non-depressed $\mathrm{MtF}$ gender dysphoria. Data from the Kebaya NGO waria Yogyakarta extended family showed that the number of $\mathrm{MtF}$ gender dysphoric individuals is 234 people spread over several areas in Yogyakarta. ${ }^{(4)}$

Gender dysphoric individuals experience more psychosocial problems such as stigma, discrimination, social support and low family support compared to lesbian, gay, bisexual (LGB) individuals. The majority of Indonesians (93\%) still reject gender dysphoria and only $3 \%$ accept it. Discrimination and shame fearing family reactions are two main reasons for gender dysphoric people not to report cases of discrimination they experience to relevant agencies, to be unwilling to document their case, and to be reluctant to seek mental health services. Gender dysphoric individuals may experience dropping out of school because of discrimination and rejection causing gender dysphoric individuals to risk social isolation, problematic academic performance, bullying behavior, feelings of inadequacy to go to school with the biological gender status, experience ostracism, harassment (sexual, physical, verbal, and emotional), persecution, humiliation, difficulty in getting employment, rejection by health care providers, and a disrespectful public attitude both in the workplace and in public places. ${ }^{(5,6)}$

The psychological aspect is strongly correlated to social stigma that ends up to the psychological pressure experienced by the gender dysphoria community. Gender dysphoria, discriminated, victimized, and stigmatized persons may be at risk of high perceived discrimination, negative self-image (feeling inferior, embarrassed, isolated and rejected by the environment, lonely, helpless, anxious, depressed, attempting suicide), emotional and mental health problems of behavior and deterioration of the quality of life. Depression and suicide attempts are two of the most common transgender mental health problems. ${ }^{(5)}$ The National Center for Transgender Equality and National Gay and Lesbian Task Force survey shows that $41 \%$ of gender dysphoric individuals attempts suicide compared with $1.6 \%$ of the general population, $32 \%$ are depressed, and $29 \%$ have somatization disorders. ${ }^{(7)}$ Acceptance as well as family and community support provide a protective effect against many of the "threats" to the well-being of gender dysphoric individuals, including the risk of HIV-AIDS infection, depression and suicide. Inadequate social and family support, especially from biological families, is often reported in the case of the individuals' sense of security when in a public setting. ${ }^{(6.7)}$

The phenomenon of various gender dysphoria problems is increasing in Indonesia. gender dysphoric individuals experience stigma and discrimination from various parties such as family, community, religion, culture and country. The role of the family is a protective factor for 
gender dysphoria in the face of stigma, discrimination, sexual identity, and in lowering the risk of mental disorders and poor quality of life. ${ }^{(7)}$ In the present study, the researchers wanted to determine the perceived discrimination in gender dysphoric individuals, which is the perception of gender dysphoric individuals of their sexual identity, unfair treatment, and stigma and discrimination from family, environment, and society. High perceived discrimination has an effect on poor adaptability and low self-esteem in the face of stigma and discrimination that can have further impacts on emotional mental disorders and poor quality of life. ${ }^{(8)}$ Early detection of perceived discrimination, self-esteem and family factors (family relationships, family support, parenting patterns) and social support for gender dysphoria in the face of stigma, discrimination and sexual identity, can be made for the prevention and early intervention of the impact inflicted. The aim of this study was to determine the role of family factors, peer support, self-esteem, perceived discrimination, depression, anxiety, and stress on the quality of life of $\mathrm{MtF}$ gender dysphoric individuals.

\section{METHODS}

\section{Research design}

The study design was cross sectional and the study took place in March - November 2016 at the Sanggar Swara Jakarta community.

\section{Study subjects}

Sanggar Swara Jakarta is one of the gender dysphoria community centers in Jakarta with about 300 male to female (MtF) and 50 female to male (FtM) gender dysphoric individuals with an age range of 14-45 years, spread over the five districts of DKI Jakarta (North Jakarta, South Jakarta, West Jakarta, East Jakarta, Central Jakarta).

The sample size in this study was $106 \mathrm{MtF}$ gender dysphoric individuals obtained for unpaired categorical analysis and 10\% drop-outs. The sample was obtained from all religions using cluster random sampling. ${ }^{(9)}$ The inclusion criteria of this research were MtF gender dysphoric individuals targeted at the five Jakarta Swara areas (South, West, East, Central, North) areas, aged 18-45 years, with no history of drug abuse, able to read and write, and agreeing to fill out questionnaires completely. Excluded from this study were those who were unwilling to sign informed consent, or were suffering from severe mental disorders (psychotic disorder and mental retardation).

\section{Measurements}

The instruments used in this study are the following eight questionnaires. The first is a demographic questionnaire consisting of age, educational level, occupation, and economic status. The second is the Rosenberg Self-Esteem Questionnaire consisting of 10 questions with 4 categories, where self-esteem is high if the total score is $\geq 15$ and low if the total score is $<15$. ${ }^{(10)}$ This study also used a perceived discrimination questionnaire consisting of 15 questions, where perceived discrimination is high if total score $>13$ and low if total score $\leq 13$ with Cronbach's alpha of $0.890{ }^{(11)}$ The questionnaire on family relations (FACES III) consists of 16 questions with 4 types of family cohesion and 4 types of family adaptability, which are further summarized in 3 types of family relationships, i.e. balanced, extreme, and mid-range family relations. ${ }^{(12)}$

The family support questionnaire consists of 20 questions with supportive results if the total score $\geq 60$ and non supportive when the total score $<60$. ${ }^{(13)}$ The social support questionnaire (SSQ6) consists of 6 questions, where the results are peer support if the total score $\geq 3$ and no peer support when the total score $<3$. $^{(14)}$ The depression anxiety stress scales (DASS) consists of 42 questions and is divided into 3 sub-scales, namely depression, anxiety and stress, each containing 14 questions. Each sub-scale has a range of values $0-3$. The total score is calculated by summing the scores of each sub-scale giving a score range of 0-42 for each sub-scale. Total scores below 10,18,15 on anxiety depression and stress sequentially 
indicate normal levels, while total scores above 20, 14 and 25 in depression, anxiety and stress sequentially indicate very severe levels. ${ }^{(15)}$ The WHOQL-BREF questionnaire consists of 24 questions where the results are good quality of life if the total score $\geq 60$ and poor quality of life when the total score $<60$. $^{(16)}$

\section{Statistical analysis}

The data of this study were analyzed using binary simple logistic regression analysis for the relationship of gender dysphoria quality of life with employment, perceived discrimination, selfesteem, family support, and anxiety. Multiple logistic regression analysis was used for the relationship of quality of life with perceived discrimination and family support. The relationships were considered to be of statistical significance at an error probability of less than $0.05(\mathrm{p}<0.05)$.

\section{Ethical clearance}

This research has been approved by the Ethical Clearance Committee, Faculty of Medicine, Atma Jaya Catholic University of Indonesia, under number 05/04/KEP-FKUAJ/ 2016-April 18, 2016.

\section{RESULTS}

\section{Characteristics of participants}

In this study, there were $106 \mathrm{MtF}$ gender dysphoric individuals of Sanggar Swara Jakarta, with the age range of 18-40 years. In this study there were no respondents who dropped out. The majority of subjects had the following characteristics: $57.5 \%$ senior high school education, $69.8 \%$ low economic status, $64.2 \%$ employed, 35.8\% residing in North Jakarta. Most of the respondents had the following pecentages of determinant factors: $62.3 \%$ high perceived discrimination, $64.1 \%$ low self-esteem, $44.3 \%$ depression, $59.4 \%$ anxiety and $35.8 \%$ stress. A total of $78.3 \%$ had no family support, $64.1 \%$ no peer support, $36.0 \%$ had extreme family relations and $62.3 \%$ poor quality of life (Table 1 ).
Table 1. Key characteristics of study respondents and other explanatory variables $(n=106)$

\begin{tabular}{|c|c|}
\hline Variables & n $(\%)$ \\
\hline \multicolumn{2}{|l|}{ Age (years) } \\
\hline $18-24$ & $34(32.1)$ \\
\hline $25-31$ & $36(34.0)^{*}$ \\
\hline $32-38$ & $26(24.5)$ \\
\hline $39-45$ & $10(9.40)$ \\
\hline \multicolumn{2}{|l|}{ Education } \\
\hline Senior high school & $55(57.5)^{*}$ \\
\hline Junior high school & $45(42.5)$ \\
\hline \multicolumn{2}{|l|}{ Occupation } \\
\hline Employed & $62(64.2)^{*}$ \\
\hline Non-employed & $38(35.8)$ \\
\hline \multicolumn{2}{|l|}{ Family Socio-economic Status } \\
\hline $\begin{array}{l}\text { Middle income } \\
\text { (Rp 3.100.000/month or above) }\end{array}$ & $26(30.2)$ \\
\hline $\begin{array}{l}\text { Low income } \\
\text { (below Rp 3.100.000/month) }\end{array}$ & $74(69.8)^{*}$ \\
\hline \multicolumn{2}{|l|}{ Region } \\
\hline North Jakarta & $38(35.8)^{*}$ \\
\hline Central Jakarta & $6(5.70)$ \\
\hline West Jakarta & $13(12.2)$ \\
\hline East Jakarta & $22(20.7)$ \\
\hline South Jakarta & $27(25.6)$ \\
\hline \multicolumn{2}{|l|}{ Perceived discrimination } \\
\hline High & $66(62.3)^{*}$ \\
\hline Low & $40(37.7)$ \\
\hline \multicolumn{2}{|l|}{ Self-esteem } \\
\hline High & $32(35.9)$ \\
\hline Low & $68(64.1)^{*}$ \\
\hline \multicolumn{2}{|l|}{ Family Support } \\
\hline Supportive & $17(21.7)$ \\
\hline Non-supportive & $83(78.3)^{*}$ \\
\hline \multicolumn{2}{|l|}{ Peer Support } \\
\hline Supportive & $32(35.9)$ \\
\hline Non-supportive & $68(64.1)^{*}$ \\
\hline \multicolumn{2}{|l|}{ Family relations type } \\
\hline Balanced & $18(16.9)$ \\
\hline Mid range & $50(47.1)^{*}$ \\
\hline Extreme & $38(36.0)$ \\
\hline \multicolumn{2}{|l|}{ Depression } \\
\hline Negative & $53(55.7)^{*}$ \\
\hline Positive & $47(44.3)$ \\
\hline \multicolumn{2}{|l|}{ Anxiety } \\
\hline Negative & $37(40.6)$ \\
\hline Positive & $63(59.4)^{*}$ \\
\hline \multicolumn{2}{|l|}{ Stress } \\
\hline Negative & $62(64.2)^{*}$ \\
\hline Positive & $38(35.8)$ \\
\hline \multicolumn{2}{|l|}{ Quality of life } \\
\hline Good & $40(37.7)$ \\
\hline Poor & $66(62.3)^{*}$ \\
\hline
\end{tabular}

Note* $=$ high percentage 
Table 2. Correlation between factors affecting quality of life in

$\mathrm{MtF}$ gender dysphoric individuals $(\mathrm{n}=106)$

\begin{tabular}{|c|c|c|c|c|c|c|}
\hline \multirow[b]{2}{*}{ Variables } & & \multicolumn{2}{|c|}{ Quality of life } & \multirow[b]{2}{*}{$\begin{array}{c}\mathbf{p} \\
\text { value }\end{array}$} & \multirow[b]{2}{*}{ OR } & \multirow[b]{2}{*}{$95 \%$ CI } \\
\hline & & $\begin{array}{l}\text { Good } \\
\text { n (\%) }\end{array}$ & $\begin{array}{l}\text { Poor } \\
\text { n }(\%)\end{array}$ & & & \\
\hline \multirow[t]{2}{*}{ Education } & Senior high school & $23(57.5)$ & $38(57.5)$ & & \multirow{2}{*}{2.4} & $11.9-45.9$ \\
\hline & Junior high school & $17(42.5)$ & $28(42.5)$ & 0.301 & & \\
\hline \multirow[t]{2}{*}{ Occupation } & Employed & $13(32.5)$ & $55(83.3)$ & & \multirow{2}{*}{0.46} & \\
\hline & Non-employed & $27(67.5)$ & $11(16.7)$ & $0.000^{*}$ & & $39.0-78.8$ \\
\hline \multirow[t]{2}{*}{ Socioeconomic Status } & Middle & $14(35.0)$ & $18(27.3)$ & & \multirow{2}{*}{4.9} & \\
\hline & Low & $26(65.0)$ & 48 (72.7) & 0.101 & & $0.78-98.5$ \\
\hline \multirow[t]{2}{*}{ Perceived discrimination } & High & $21(52.5)$ & $45(68.2)$ & & \multirow{2}{*}{12.70} & \\
\hline & Low & $19(47.5)$ & $21(31.8)$ & $0.004^{*}$ & & $29.8-76.55$ \\
\hline \multirow[t]{2}{*}{ Self-esteem } & High & $11(27.5)$ & $27(40.9)$ & & \multirow[t]{2}{*}{2.89} & \multirow[t]{2}{*}{$34.1-56.2$} \\
\hline & Low & $29(72.5)$ & $39(59.1)$ & $0.001 *$ & & \\
\hline \multirow[t]{2}{*}{ Depression } & Negative & $26(65.0)$ & $33(50.0)$ & & \multirow[t]{2}{*}{6.7} & \multirow[t]{2}{*}{$0.21-33.56$} \\
\hline & Positive & $14(35.0)$ & $33(50.0)$ & 0.209 & & \\
\hline \multirow[t]{2}{*}{ Anxiety } & Negative & $13(32.5)$ & $30(45.5)$ & & \multirow[t]{2}{*}{2.15} & \multirow[t]{2}{*}{$22.9-42.8$} \\
\hline & Positive & $17(67.5)$ & $36(54.5)$ & $0.002 *$ & & \\
\hline \multirow[t]{2}{*}{ Stress } & Negative & $21(52.5)$ & $47(71.2)$ & 0.602 & \multirow[t]{2}{*}{1.8} & \multirow[t]{2}{*}{$0.81-92.7$} \\
\hline & Positive & $19(47.5)$ & $19(28.8)$ & & & \\
\hline \multirow[t]{2}{*}{ Family support } & Support & $14(35.0)$ & $18(37.3)$ & & \multirow[t]{2}{*}{23.19} & \multirow[t]{2}{*}{$37.1-59.1$} \\
\hline & No support & $26(65.0)$ & $48(72.7)$ & $0.000 *$ & & \\
\hline \multirow[t]{2}{*}{ Peer support } & Support & $14(35.0)$ & $14(21.2)$ & & \multirow[t]{2}{*}{3.5} & \multirow{2}{*}{$0.42-67.5$} \\
\hline & No support & $26(65.0)$ & $52(78.8)$ & 0.407 & & \\
\hline \multirow[t]{3}{*}{ Family relations type } & Balanced & $6(15.0)$ & $13(19.7)$ & 0.605 & 2.9 & $0.52-23.8$ \\
\hline & Extreme & $13(32.5)$ & $40(60.6)$ & & \multirow{2}{*}{1 (Reference) } & \\
\hline & Mid range & $21(52.5)$ & $13(19.7)$ & 0.306 & & $0.34-19.6$ \\
\hline
\end{tabular}

$\mathrm{OR}=$ Odds Ratio

Table 2 shows that there were 5 variables (employment, perceived discrimination, selfesteem, family support, and anxiety) significantly associated with life quality $(\mathrm{p}<0.05)$. But there was no significant relationship of educational level, socioeconomic status, type of family relation, peer support, stress, and depression with quality of life $(p>0.05)$. The study showed that $83.3 \%$ of employed respondents had poor quality of life and $16.7 \%$ of non employed respondents had poor quality of life. There were $31.8 \%$ of respondents with low perceived discrimination who had poor quality of life and $68.2 \%$ of respondents with high perceived discrimination who had poor quality of life. There were $40.9 \%$ of respondents with high self-esteem who had poor quality of life and $59.1 \%$ of respondents with low self-esteem who had poor quality of life. There were $72.7 \%$ of respondents without family support who had poor quality of life and $37.3 \%$ of respondents with family support who had poor quality of life. This study also showed that $45.5 \%$ respondents with anxiety had poor quality of life and $54.5 \%$ respondents without anxiety had poor quality of life.

Table 3. Factors associated with quality of life in MtF gender dysphoric individuals ( $\mathrm{n}=106)$

\begin{tabular}{lcccc}
\hline \multirow{2}{*}{ Variable } & p value & \multirow{2}{*}{ Adjusted OR $^{\circledR}$} & \multicolumn{2}{c}{$\mathbf{9 5 \%}$ CI for EXP(B) } \\
\cline { 4 - 5 } & & & Lower & Upper \\
\hline Occupation & 0.201 & 1.79 & 1.925 & 3.422 \\
Family support & $0.000^{*}$ & 29.11 & 5.899 & 11.990 \\
Perceived discrimination & $0.004^{*}$ & 23.89 & 2.455 & 8.210 \\
Self-esteem & 0.069 & 11.61 & 5.201 & 23.901 \\
Anxiety & 0.169 & 6.78 & 12.221 & 26.701 \\
Socioeconomic status & 0.109 & 1.89 & 9.760 & 14.109 \\
Depression & 0.089 & 3.78 & 10.675 & 21.670 \\
\hline
\end{tabular}


Table 3. Factors associated with quality of life in $\mathrm{MtF}$ gender dysphoric individuals $(\mathrm{n}=106)$

\begin{tabular}{lccrr}
\hline \multirow{2}{*}{ Variable } & \multirow{2}{*}{$\mathbf{2}$} & Adjusted OR $^{\circledR}$ & \multicolumn{2}{c}{$\mathbf{9 5 \%}$ CI for EXP (B) } \\
\cline { 4 - 5 } Occupation & 0.201 & 1.79 & Lower & Upper \\
Family support & $0.000^{*}$ & 29.11 & 1.925 & 3.422 \\
Perceived discrimination & $0.004^{*}$ & 23.89 & 5.899 & 11.990 \\
Self-esteem & 0.069 & 11.61 & 2.455 & 8.210 \\
Anxiety & 0.169 & 6.78 & 5.201 & 23.901 \\
Socioeconomic status & 0.109 & 1.89 & 12.221 & 26.701 \\
Depression & 0.089 & 3.78 & 10.760 & 14.109 \\
\hline
\end{tabular}

Note: $\mathrm{CI}=95 \%$ confidence interval for the mean; $\mathrm{p}^{*=}$ significant association; ${ }^{\circledR}$ Adjusted odds ratio controlled for variables

The binary logistic regression test showed different proportions of quality of life between subjects who were employed and those who were non-employed $(\mathrm{OR}=0.46, \mathrm{p}=0.000)$, between subjects with low and high perceived discrimination $(\mathrm{OR}=12.70, \mathrm{p}=0.004)$, and between low and high self-esteem $(\mathrm{OR}=2.89, \mathrm{p}=0.001)$, without family support and with family support $(\mathrm{OR}=23.19, \mathrm{p}=0.000)$, and with and without anxiety $(\mathrm{OR}=2.15, \mathrm{p}=0.002)$, respectively (Table 2).

There were no significant relationships of educational levels, socio-economic status, type of family relations, peer support, stress, and depression with quality of life ( $p>0.05)$. A total of $57.5 \%$ of respondents who were senior high school graduates and $42.5 \%$ of respondents who were junior high school graduates had poor quality of life. The study also showed that $69.8 \%$ of respondents with low economic status and $30.2 \%$ respondents with middle economic status had poor quality of life. The study also showed that $60.6 \%$ of respondents with extreme family relationships and $19.7 \%$ respondents with balanced family relationships had poor quality of life. A total of $78.8 \%$ respondents without peer support had poor quality of life and $21.2 \%$ respondents with peer support had poor quality of life. The results of this study showed that $28.8 \%$ of respondents with stress had poor quality of life and $71.2 \%$ without stress had poor quality of life. There were $50 \%$ of respondents with depression who had poor quality of life and $50 \%$ of respondents without depression who had poor quality of life. The proportion of quality of life was not significantly different between subjects with senior and junior high school level ( $\mathrm{p}=0301)$; low and middle economic status ( $\mathrm{p}=0.101)$; extreme and balanced family type $(\mathrm{p}=0.605)$; peer support and no peer support ( $\mathrm{p}=0.407)$; stress and no stress $(\mathrm{p}=0.602)$; depression and no depression $(p=0.209)$ (Table 2).

\section{Multivariate analysis}

The results of multivariate logistic regression analysis showed that there were two influencing variables, i.e. perceived discrimination and family support. The variable perceived discrimination had an odds ratio of 13.89 (95\%CI: 5.89-11.99), which means that respondents with high perceived discrimination had a 13.89-fold greater risk for poor quality of life. The variable family support had an odds ratio of 29.11 (95\%CI: 2.45-8.21), which means that respondents without family support had a 29.11 times greater risk for poor quality of life (Table 3).

\section{DISCUSSION}

The result of this study indicate that among the $106 \mathrm{MtF}$ gender dysphoric individuals in the age range of 18-45 years, the majority of respondents have high school education, most are employed as sex workers, the rest work as salon employees, salon owners, and buskers. They have a low economic status (earning less than $\mathrm{Rp}$ $3.100 .000 /$ month) and most live in villages, occupying a narrow boarding-house room. Research by Prabawanti et al. ${ }^{(17)}$ in $\mathrm{MtF}$ gender dysphoric individuals in DKI Jakarta showed that $42 \%$ had junior high school education, $60 \%$ were commercial sex workers $(34.9 \%$ as sex worker 
for their main income and $24.4 \%$ for additional income). Nuttbrock et al. ${ }^{(18)}$ showed that most of the MtF gender dysphoria individuals experiences discrimination and tend to have no choice in running their lives in the community. The large number of constraints from the environment, access to education, access to health and the right to decent work leads to low-income, low-paid work, and sex work.

The results of our study showed that $62.3 \%$ of respondents had high perceived discrimination, and $64.1 \%$ had low self-esteem. Bazargan and Galvan state ${ }^{(19)}$ that discrimination experienced by transgender individuals may be physical or sexual violence, social exclusion, humiliation, being viewed as a sex worker and as HIV positive, discrimination at work and health services. Gender dysphoric individuals suffering from discrimination and stigmatization have a low selfesteem that can have further impacts with emotional mental disorders, suicide and poor quality of life.

The results of the present study indicate that $59.4 \%$ of respondents had anxiety, $44.3 \%$ depression and $35.8 \%$ stress. Bockting et al. ${ }^{(3)}$ showed 52\% respondents with anxiety, $48.7 \%$ depression and $25.1 \%$ stress. Depression and suicide attempts are the most common conditions in transgender mental health problems. The survey of the National Center for Transgender Equality and the National Gay and Lesbian Task Force stated that the prevalence of depression in transgender was $44.1 \%$, among them $41 \%$ suicide attempts, while depression in the general population was $6.6 \%$ and suicide attempts $1.6 \%$. There were more suicide attempts by transgender individuals who have lost their jobs due to a negative view of their transgender status, are targets of bullying or bullying at school, or victims of physical or sexual abuse. ${ }^{(20)}$

The results of our study also showed that $78.3 \%$ of respondents did not receive family support, $64.1 \%$ did not receive social support, and $36 \%$ had extreme family relations. This study is in accordance with the study by Simon et al. ${ }^{(21)}$ which showed that $74 \%$ of gender dysphoric individuals did not have family support, $59.2 \%$ were not socially supported, and $27 \%$ had extreme family relations. Gender dysphoric individuals who do not get family or social support have a greater risk of depression and suicidal ideation than those who get family or social support. Two studies in India found that $20.1 \%$ of gender dysphoric individuals who did not get family support could experience greater discrimination and violence at home than the $0.4 \%$ who received family support. Family rejection of gender dysphoric individuals took the form of judging them to be a "disgrace" to the family. Relationship factors between family members and the environment can affect a family's refusal of gender dysphoria as individuals "neighbors" that can trigger gender dysphoria behavior by the family and most gender dysphoric individuals leave the house. Low family support is due to the inability of families to adapt and accept their gender dysphoria family members. ${ }^{(20,21)}$

The results of the present study showed that $62.3 \%$ of respondents had poor quality of life. George ${ }^{(22)}$ showed that gender dysphoric individuals without family support led them to become homeless, employed as sex worker, and make suicide attempt. The National Transgender Discrimination Survey (NTDS) showed that 19\% gender dysphoric individuals were expelled from residence, more than 2.5 times more likely to be jailed, 4 times more likely to work as sex workers, 3 times more likely to be HIV positive and 4 times more likely to make suicide attempts. The National Transgender Discrimination Survey also showed that $28 \%$ of gender dysphoric individuals delayed seeking health services due to discrimination, $48 \%$ did not have sufficient funds, and 19\% experienced denial of health services. Limited access to health services occurs because rejection or prejudice and lack of knowledge of health care workers on gender dysphoric individuals, making it difficult for these to obtain appropriate and competent health services. ${ }^{(23)}$ 
Our study showed that occupation, perceived discrimination, self-esteem, family support, and anxiety were significantly associated with quality of life. Bar et al. ${ }^{(24)}$ showed that most of the MtF gender dysphoric individuals experiences discrimination that tends to leave them no choice in running their lives in society. The many barriers of access to education and the right to decent work cause many of the gender dysphoric individuals to be of low income and low education, and employed in sex work. Prabawanti et al. ${ }^{(17)}$ argues that the frequently stigmatized and discriminated $\mathrm{MtF}$ gender dysphoric individuals are forced to become sex workers because it is difficult to compete for decent jobs in Jakarta, with a degree of education that is limited to junior and senior high school. Despite employment opportunities, transgender individuals are often denied work because of their identity as transgender individuals and are judged as a violation of community values and norms. Gender dysphoria people who are employed as sex workers have poorer mental, physical, psychological and social health than gender dysphoria people who are not employed as sex workers, experience higher stigma and discrimination and have a higher risk of drug abuse, physical and sexual abuse, as well as HIV disease or other sexually transmitted diseases that end in emotional and behavioral disorders and poor quality of life..$^{(20.24)}$

The result of our study showed there were two variables, i.e. perceived discrimination and family support that were associated with quality of life. The most dominant variable was family support, which affects the quality of life of transgender $\mathrm{MtF}$ individuals.

The study by Burgess et al. ${ }^{(25)}$ suggested that unfavorable family support poses a 5.72 times greater risk for anxiety, while the risk of depression is 4.06 times, and suicide risk is 3.09 times compared with proper family support. Family support has the strongest positive effect on mental health and the survival of transgender life. The majority of families will reject family members who take the liberty to express themselves as gender dysphoric individuals, who are judged as a disgrace to the family, as sinners, as exposing the shame of the family to the neighbors, and various other negative stigmata. Family rejection of gender dysphoric individuals always occur, being only different in the type of rejection, from refusal to acknowledge them to refusal that leads to physical violence even to their being expelled from home. ${ }^{(26)}$ Nemoto et al. ${ }^{(27)}$ stated that $\mathrm{MtF}$ gender dysphoric individuals who do not have family or social support have a greater suicide risk than those receiving social and family support.

Weissman's ${ }^{(28)}$ study reported that $54.8 \%$ of gender dysphoric individuals had high perceived discrimination. Basar et al. ${ }^{(29)}$ stated that high perceived discrimination, poor social support, and poor family support can affect self-esteem and gender dysphoria mental health by degrading the quality of life. Prabawanti et al. ${ }^{(17)}$ stated that $\mathrm{MtF}$ gender dysphoric individuals are often stigmatized and discriminated, forcing them to become sex workers because it is difficult to compete for employment in Jakarta, when only having a high school education. Although discriminatory acts are legally prohibited, $\mathrm{MtF}$ gender dysphoric individuals experience discrimination that causes difficulties in completing education, job search, housing ownership and access to general health services. Wilson et al..$^{(0)}$ stated that $61 \%$ of $\mathrm{MtF}$ gender dysphoric individuals have difficulties in obtaining jobs due to stigma and discrimination, so they look to sex work for alternatives.

The limitation of this study is the crosssectional design used, that cannot explain any causal relationship of perceived discrimination and family support with male to female (MtF) gender dysphoric individuals' quality of life. Further research is needed with longitudinal research design to be able to explain causal relationships. The present research was conducted on MtF gender dysphoric individuals in the community of Sanggar Swara Jakarta spread over the five municipal areas of the DKI Jakarta special capital city area with unequal 
numbers of respondents in the five regions. It is hoped that through the results of this research there may be early detection of psychological problems, stigma and discrimination, emotional mental disorders in transgender individuals and attempts at comprehensive intervention by involving the family or parents so as to achieve good quality of life for gender dysphoric individuals and their families.

Further research can be done on gender dysphoria of both male to female $(\mathrm{MtF})$ or female to male (FTM) types on the role of family factors, especially family support for family members with gender dysphoria. Family support and good family communication can help the gender dysphoria individual to face acceptance of their sexual identity, self-esteem, decrease perceived discrimination, prevent emotional and behavioral mental disorders and obtain a good quality of life

\section{CONCLUSION}

High perceived discrimination and no family support are high risk factors for emotional and behavioral mental disorders and poor quality of life for gender dysphoria people especially male to female $(\mathrm{MtF})$ gender dysphoric individuals.

\section{CONFLICT OF INTEREST}

There are no conflicts of interest

\section{ACKNOWLEDGMENT}

We thank all male to female (MtF) gender dysphoric individuals in Sanggar Swara Jakarta community who have been willing to participate in this research and all the health care staff of Sanggar Swara Jakarta who have helped in this research.

\section{CONTRIBUTORS}

S contributed to drafting and designing the study. S, YA, CCl and SSK contributed to conducting the study. S and YA supervised and/ or performed the data management and data entry. S, YA, CC and SSK contributed to analysis and interpretation of the data. All authors read and approved the final manuscript.

\section{REFERENCES}

1. Bradford J, Reisner SL, Honnold JA, et al. Experiences of transgender-related discrimination and implications for health: results from the Virginia Transgender Health Initiative Study. Am J Public Health 2013;103:1820-9.

2. Abigail, S. Regional feature: the GWL-INA: the formation of a national network of gay men, transgender and MSM in Indonesia. HIV Australia 2012;10:43.

3. Bockting WO, Miner MH, Swinburne RE, et al. Stigma, mental health, and resilience in an online sample of the US transgender population. Am J Public Health 2013;103:943-51.

4. Prabawanti C, Bollen L, Palupy R, et al. HIV, sexually transmitted infections, and sexual risk behavior among transgenders in Indonesia. AIDS Behav 2011;15:663-73.

5. Zelle A, Arms T. Psychosocial effects of health disparities of lesbian, gay,bisexual, and transgender older adults. J Psychosoc Nurs Ment Health Serv 2015;53:25-30.

6. Kaiser CR, Major B. A social psychological perspective on perceiving and reporting discrimination. Law Soc Inq 2006;31:801-30.

7. Belkin A. Caring for our transgender troops-the negligible cost of transition-related care. $\mathrm{N}$ Engl J Med 2015;373:1089-92.

8. Pascoe EA, Smart RL. Perceived discrimination and health: a meta-analytic review. Psychol Bull 2009;135:531-54.

9. Sopiyudin MD. Besar sampel dan cara pengambilan sampel dalam penelitian kedokteran dan kesehatan. Edisi 2. Jakarta: Salemba Medika; 2009.

10. Robins RW, Hendin HM, Trzesniewski KH. Measuring global self-esteem:construct validation of a single-item measure and the Rosenberg self-esteem. PSPB 2001:27:151-61.

11. Bradford J, Reisner SL, Honnold JA, et al. Experiences of transgender-related discrimination and implications for health: results from the Virginia Transgender Health Initiative Study. Am J Public Health 2013;103:1820-9.

12. Place M, Hulsmeier J, Brownrigg A, et al. The family adaptability and cohesion evaluation scale (FACES): an instrument worthy of rehabilitation. Psychiatrist 2005;29:215-8. 
13. Pastrana A. Being out to others: the relative importance of family support, identity and religion for LGBT latinas/os. Lat Stud 2015;13:88-112.

14. Alexander A, Mustafa A, Emil SAV, et al. Social support during delivery in rural central Ghana: a mixed methods study of women's preferences for and against inclusion of a lay companion in the delivery room. J Biosoc Sci 2014;46:669-85.

15. Tran TD, Fisher J. Validation of the depression anxiety stress scales (DASS) 21 as a screening instrument for depression and anxiety in a rural community-based cohort of northern Vietnamese women. BMC Psychiatry 2013;13:24. doi:10.1186/ 1471-244X-13-24.

16. Yang X, Zhao L, Wang L, et al. Quality of life of transgender women from China and associated factors: a cross-sectional study. J Sex Med 2016;6: 977-87. doi: 10.1016/j.jsxm.2016.03.369.

17. Prabawanti C, Dijkstra A, Riono P, et al. A survey on HIV-related health-seeking behaviors among transgender individuals in Jakarta, based on the theory of planned behavior. BMC Public Health 2015;15:1138. doi:10.1186/s12889-015-2480-0.

18. Nuttbrock L, Bockting W, Rosenblum A, et al. Gender abuse, depressive symptoms, and substance use among transgender women: a 3year prospective study. Am J Public health 2014; 104:2199-206.

19. Bazargan M, Galvan F. Perceived discrimination and depression among low-income Latina maleto-female transgender women. BMC Public Health 2012;2:663. doi: 10.1186/1471-2458-12-663.

20. Poguri M, Sarkar S, Hawa SN. A pilot study to assess emotional distress and quality of life among transgender in South India. J Neuropsychiatry 2016;2:1-13.

21. Bariola E, Lyons A, Leonard W, et al. Demographic and psychosocial factors associated with psychological distress and resilience among transgender individuals. Am J Public Health 2015; 105:2108-16.

22. George A, Janardhana N, Muralidhar D. Quality of life of transgender older adult. Int J Soc Sci Humanit Invent 2015;4:7-11.
23. Wilson EC, Chen YH, Arayasirikul S, et al. The impact of discrimination on the mental health of trans female youth and the protective effect of parental support. AIDS Behav 2016;20:2203-11. doi:10.1007/s10461-016-1409-7.

24. Bar MA, Jarus T, Wada M, et al. Male-to-female transitions: Implications for occupational performance, health, and life satisfaction. Les transitions homme-femme/ : conséquences en matière de rendement occupationnel, de sante et de satisfaction face a la vie. Can J Occup Ther 2016;83:72-82.

25. Burgess D, Lee R, Tran A, et al. Effects of perceived discrimination on mental health and mental health services utilization among gay, lesbian, bisexual and transgender persons. J LGBT Health Res 2008:3:1-14.

26. Simon L, Schararger SM, Clacrk LF, et al. Parental support and mental health among transgender adolescents. J Adolesc Health 2013;53:791-3. doi: 10.1016/j.jadohealth.2013.07.019.

27. Nemoto T, Bödeker B, Iwamoto M. Social support, exposure to violence and transphobia, and correlates of depression among male-to-female transgender women with a history of sex work. Am J Public Health 2011;101:1980-8.

28. Weissman A, Ngak S, Srean C, et al. HIV prevalence and risks associated with HIV infection among transgender individuals in Cambodia. PLoS ONE 2016;11:e0152906. doi:10.1371/journal.pone.

29. Basar K, Gokhan O, Jale K. Perceived discrimination, social support, and quality of life in gender dysphoria. J Sex Med 2016;7:1133-41. doi: 10.1016/j.jsxm.2016.04.071.

30. Wilson EC, Garofalo R, Harris RD, et al. Transgender female youth and sex work: HIV risk and a comparison of life factors related to engagement in sex work. AIDS Behav 2009;13: 902-13. 